\title{
Analyzing the Causes of Spatial Differentiation of the Traditional Villages in Gansu Province, Western China
}

\author{
Jianglei Jin1,2,3, Haowen Yan 1,2,3* \\ ${ }^{1}$ Faculty of Geomatics, Lanzhou Jiaotong University, Lanzhou, China \\ ${ }^{2}$ Gansu Provincial Engineering Laboratory for National Geographic State Monitoring, Lanzhou, China \\ ${ }^{3}$ National-Local Joint Engineering Research Center of Technologies and Applications for National Geographic State Monitoring, \\ Lanzhou, China \\ Email: jinjianglei@lzjtu.edu.cn, *haowen2010@gmail.com
}

How to cite this paper: Jin, J. L., \& Yan, H. W. (2020). Analyzing the Causes of Spatial Differentiation of the Traditional Villages in Gansu Province, Western China. Journal of Geoscience and Environment Protection, $8,12-25$.

https://doi.org/10.4236/gep.2020.810002

Received: September 8, 2020

Accepted: October 11, 2020

Published: October 14, 2020

Copyright $\odot 2020$ by author(s) and Scientific Research Publishing Inc. This work is licensed under the Creative Commons Attribution International License (CC BY 4.0).

http://creativecommons.org/licenses/by/4.0/

\begin{abstract}
The study and protection for traditional villages are very important for us to protect Chinese historical and cultural heritage. Data show that under the condition of rapid urbanization. The number and coverage of traditional villages in western China are decreasing. It is impossible to effectively protect a large number of rural settlements at the bottom of China's traditional settlement system. Therefore, it is necessary to explore the spatial survival status of traditional villages and protect them comprehensively and extensively. Using the digital elevation model (DEM) data of traditional villages in Gansu Province, China, published by the Ministry of Housing and Urban Development and the attribute data obtained by the Statistics Bureau of Gansu Province, China, the nuclear density, the Mulan indices, the correlations between the heights and the centers are calculated and used to study the spatial different characteristics of the villages, and a number of results have been achieved: 1) In spatial differentiation, the spatial agglomeration of the villages is obvious and different, which can be seen by the distribution of the villages from along the upper reaches of the Yellow River to the southeast, and the distribution of prefecture-level cities is related to the landforms. 2) In vertical spatial distribution, the span of the altitude data is large. Among the villages, the Zagana Village in Diebu County of Gannan City is the highest and the Zhengjiashe Village in Bingkou Town of Longnan City is the lowest. With the increase of altitude, the number of traditional villages generally shows a tendency of decrease. 3) The spatial differentiation of the traditional villages has a clear normal distribution with the elevation, and the spatial differentiation is low, showing a distinct gourd-like structure; the eastern and southern regions are more concentrated, while the northern and western regions are less concen-
\end{abstract}


trated. 4) The spatial differences of the traditional villages have the characteristics of regional differences, which are weakly related to the distance between the central cities and occur mainly in the Longnan mountain regions, the Loess Plateau in the middle of Longzhong and the Gannan plateau. The results of this study are a useful support in protection of traditional villages in provincial scale. It helps to enhance the integrity and systematicness of the protection of the spatial distribution of traditionally villages. The Chinese government had put forward the "Poverty alleviation strategy" to help Gansu Province to get out of the villages' trouble. Viewed from this angle, the research for effective patterns of traditional villages' protection and exploitation plays a crucial role in the development of China's "Poverty Alleviation Strategy".

\section{Keywords}

Traditional Villages, Spatial Differentiation, Gansu Province

\section{Introduction}

Traditional villages are the villages that well preserve their historical features, have unique folk customs, and their inner architectural environment, architectural style and locations have little change after years and are still serving the people today (Cao \& Zhang, 2013). It is of significance to study the spatial differentiation of traditional villages at different scales, such as the natural environment, folk culture and architectural landscape of the villages, for the distribution and influential factors of traditional villages in different regions are useful tools in sustainable development of rural areas and protection of traditional villages (Jin, 1988).

The spatial distribution of traditional villages is the result of the combination of natural, social and historical factors (Brunhes \& Bates, 1913). The selection of spatial location reflects the history, current situation and future direction of the evolution of rural space. The study of spatial distribution mainly focuses on the location characteristics and structural types of villages, as well as the building forms and materials related to habitat conditions (Packman \& Pacione, 1986). Rural population migration, land use patterns and environmental policy changes, rural settlement planning and other aspects have been greatly enriched, and the research results on spatial evolution rules and patterns of rural settlements have become increasingly abundant (Hudson, 1969; Bylund, 1960; Pacione, 1984; Lewis, 1986). Past achievements in traditional villages study are mainly in settlement cultures (Vos \& Meekes, 1999; Lipsky, 1995), village landscapes (Lepp, 2007; Marschalek, 2008; Scott \& Murray, 2009), and sustainable development of villages (Kastenholz et al., 2012; Chen \& Nakama, 2010; Sterkenburg, 1990; Madu, 2010). Spatial distribution characteristics and patterns of traditional Chinese villages have also been studied (Kang et al., 2016; Tong, 2014; Liu et al., 2014). Lu et al. (2004) and Ji et al. (2015) analyzed spatial scale, 
spatial evolution process and influential factors of traditional villages. Many other explorations are on spatial syntactic forms, influential factors and ethnic characteristics of traditional villages at the provincial level (Xiong, 2014; Liu et al., 2010; Sun et al., 2017; Yuan et al., 2017; Feng et al., 2017; Tong \& Long, 2007; Li et al., 2015). The literature studied the spatial distribution characteristics of rural settlements in low mountainous and hilly areas of the Loess Plateau, loess hilly areas of Longzhong, and mountain hill transition areas from the perspective of local special areas (Liang \& Zhao, 2001; Jiao et al., 2013; Guo et al., 2013; Ma, Li, \& Shen, 2012; Xia et al., 2020).

There are many enlightenments that can be gleaned from studying traditional villages at the macro-level, local distribution characteristics and influential factors of traditional villages in the above-mentioned literature, but there is a lack of in-depth study on different spatial scales at the regional level of Gansu Province. Therefore, on the basis of previous studies, using geographic information systems (GIS) and Geo-Statistics as tools, this paper intends to explore spatial differentiation characteristics of 36 national-level traditional villages in Gansu Province for the purpose of providing a reference for the protection of traditional villages.

\section{Materials and Methods}

\subsection{Study Areas}

Gansu is situated in the west of China, between northern latitude $32^{\circ} 11^{\prime}$ and $42^{\circ} 57^{\prime}$, and eastern longitude $92^{\circ} 13^{\prime}-108^{\circ} 46^{\prime}$. The topographic shape of Gansu Province is narrow and long. The provincial territory of Gansu Province is 1655 $\mathrm{km}$ long from east to west and $530 \mathrm{~km}$ wide from north to south. It is dominated by plateau and mountain areas. Its landform is complex and diverse. Mountains, plateau, plains, valleys and deserts distribute in the province (Figure 1).

There are 12 prefecture-level cities, two autonomous prefectures and 86 counties (cities and districts), including four county-level cities, 58 counties, seven ethnic autonomous counties and 17 municipal districts. As shown in Table 1, the province is divided into six types of topographic areas: Longnan Mountains, Longzhong Loess Plateau, Gannan Plateau, Qilian Mountains, Hexi Corridor, and Beishan Mountains. Since 2012, Gansu Province has four batches of 36 villages listed in the list of traditional Chinese villages published by the Ministry of Housing and Construction, accounting for $0.87 \%$ of the country's 4153 traditional villages, ranking the $21^{\text {st }}$ among the provinces in China. Because Gansu Province is located in the northwestern inland and its economy is underdeveloped, the inheritance and protection of the traditional villages are not done well in past years.

\subsection{Data Source}

Based on the application program interface (API) of the Baidu map application program, the longitude and latitude coordinates of the 36 national traditional villages in four batches in Gansu Province published by the Ministry of Con- 
struction, China were obtained, and the distribution map was constructed. From the statistical data of Gansu Provincial Bureau and the work reports of the prefecture-level governments of Gansu Province, the attribute data of the terrain areas were obtained. The digital elevation model (DEM) data of the traditional villages were captured by the Google Earth Pro.

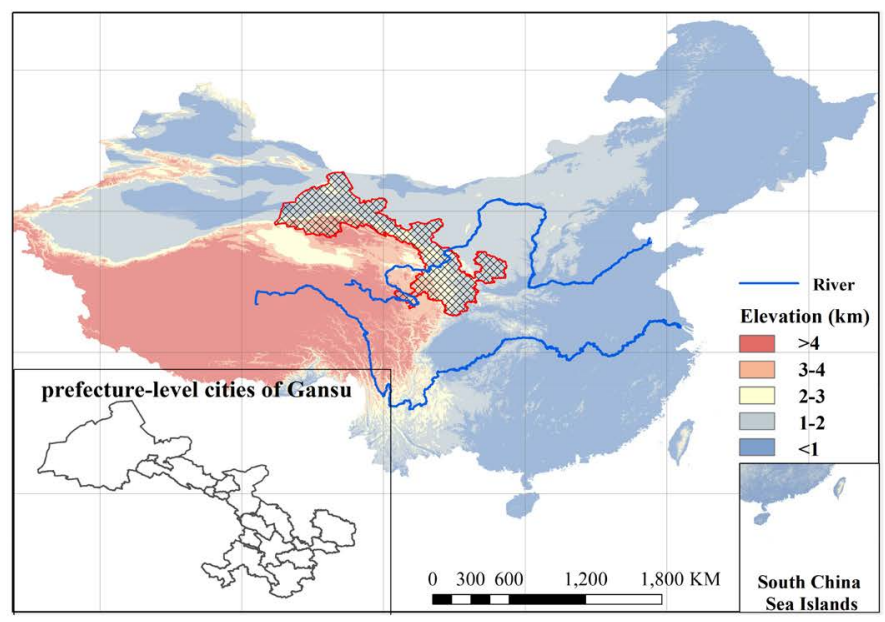

(a)

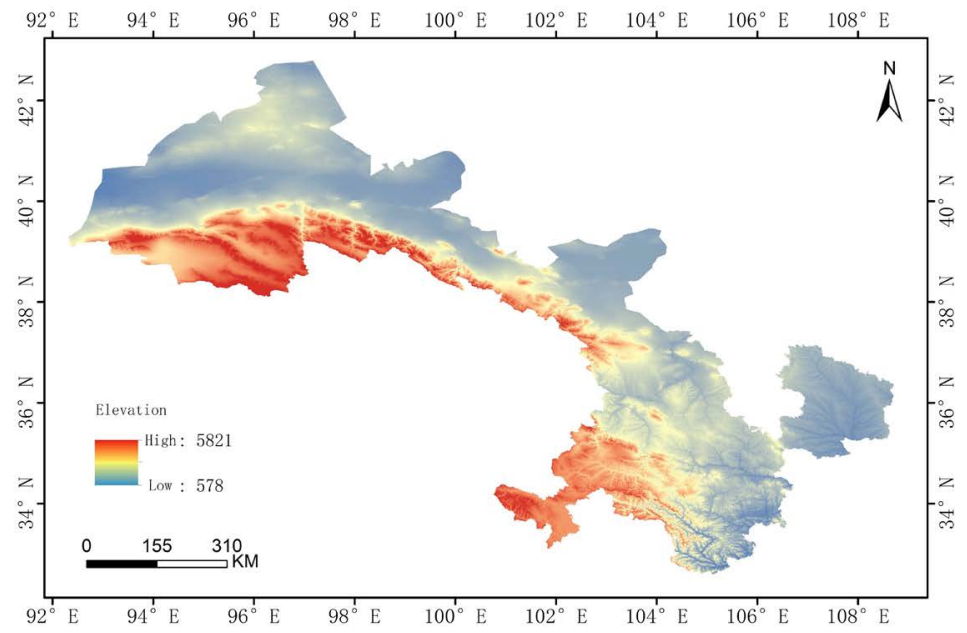

(b)

Figure 1. Study area (a) and elevation distribution (b).

Table 1. Distribution of cities in topographic areas in Gansu Province.

\begin{tabular}{ll}
\hline Topographic Area & City \\
\hline Longnan Mountain Area & Longnan \\
Longzhong Loess Plateau & Lanzhou, Silver, Tianshui, Linxia, Dingxi, Qingyang, Pingliang \\
Gannan Plateau & Gannan \\
Qilian Mountains & Zhangye \\
Hexi Corridor & Wuwei, Zhangye (Ganzhou), Jinchang, Jiuquan (Suzhou), Jiayuguan \\
Beishan Mountain & North of Shule River in Jiuquan City \\
\hline
\end{tabular}




\section{Research Ideas and Methods}

In this study, Google Earth Pro was used to determine the geographical coordinates and elevations of the traditional villages according to their addresses. By calculating the distance between traditional villages and its central location, combining the DEM data, the spatial database of the traditional villages was established. Using the methods of spatial analyses and metrologically geo-statistical analyses, the land was registered on the basis of a 1:50,000 topographic map of Gansu Province.

\subsection{Kernel Density}

The kernel density estimation method is a nonparametric method (Kang et al., 2016) used to estimate the distribution density function. Assuming that the distribution density function of the kernel density estimation method is $f$, the calculation of kernel density is as follows:

$$
\hat{f}_{h}(x)=\frac{1}{n h} \sum_{i=1}^{n} k_{h}\left(\frac{x-x_{i}}{h}\right)
$$

where, $k_{h}\left(\frac{x-x_{i}}{h}\right)$ is the kernel function; $h$ is the bandwidth, and $h>0$ is the smoothing parameter, which is the main factor affecting the kernel density estimation.

\subsection{Global Spatial Autocorrelation (Moran's I)}

The global spatial autocorrelation index is used to analyze the spatial characteristics of the attribute values of geographic data in the whole research area (Tong, 2014). Moran's I is a method to test the global clustering, and the calculation formula is as follows:

$$
\begin{gathered}
I(d)=\frac{\sum_{i=1}^{n} \sum_{j=1}^{n} w_{i j}\left(x_{i}-\bar{x}\right)\left(x_{j}-\bar{x}\right)}{S^{2} \sum_{i=1}^{n} \sum_{j=1}^{n} w_{i j}} \\
S^{2}=\frac{1}{n} \sum_{i=1}^{n}\left(x_{i}-\bar{x}\right)^{2}
\end{gathered}
$$

where, $x_{i}$ represents the observed value of the object at $i$; and $\bar{x}=\frac{1}{n} \sum_{i=1}^{n} x_{i}$ is the spatial weight value.

\subsection{Normal Distribution}

The normal distribution, also known as the Gaussian distribution, is a common method of probability distribution in geographical statistics. The function is as follows:

$$
f(x)=\frac{1}{\sigma \sqrt{2 \pi}} \mathrm{e}^{-\frac{(x-\mu)^{2}}{2 \sigma^{2}}}
$$


In the formula, $x$ is a variable; $\mu$ is the expected value; $\sigma^{2}$ is the standard deviation; and the Gaussian distribution is bell curve of $X \sim N\left(\mu, \sigma^{2}\right)$.

\section{Results and Analysis}

\subsection{Density Spatial Differentiation}

Google Earth (Google Inc., Mountain View, CA, US) was used to locate the traditional villages in Gansu Province, mark the central location of residential areas and extract geographic information in order to directly reflect the regular patterns of spatial differentiation using Arcgis10.0 (Environmental Systems Research Institute Inc., Redlands, US) for visual expression of density mapping and spatial differentiation as shown in Figure 2. The density distribution of traditional villages in Gansu Province has great regional differences, with an average distribution density of 0.78 , mainly concentrated in Longnan, Baiyin, Lanzhou, Gannan, and other cities and prefectures. There are 16 cities in Longnan, with a density of 5.73, ranking the first in the province; the values for Lanzhou, Baiyin, and Tianshui are 3.06, 2.36, and 2.08, respectively. There are no traditional villages in Dingxi, Jiayuguan, Jinchang, Jiuquan, and Wuwei.

According to the statistics of the spatial differentiation of each prefecture and city, the hierarchical settings in the layer attributes were used for visual expression to obtain the distribution of traditional villages. Figure 2 shows the centralized distribution of the traditional villages in the prefectures and cities of Gansu Province. The distribution of the traditional villages in Gansu Province is uneven, with obvious spatial agglomeration characteristics. According to the degree of agglomeration, they are the mountain agglomeration area in South Gansu, the Loess Plateau agglomeration area in Central Gansu and the plateau agglomeration area in South Gansu.

This paper analyzes the spatial distribution density of traditional villages in Gansu Province by using the intuitionistic and smooth kernel density estimation method, and uses kernel, an integrated kernel density tool in spatial analysis, to estimate the kernel density. In order to reflect the spatial distribution situation of the traditional villages in Gansu Province as a whole, considering the distance between the traditional villages and the central cities, the bandwidth was set at 30 and $50 \mathrm{~km}$, and the distribution of core density of the traditional villages in Gansu Province is shown in Figure 3 and Figure 4. The results show that the spatial differentiation of the traditional villages in Gansu Province is a low-value aggregation, and the spatial shape shows an obvious a gourd-like structure, that is, the traditional villages in Gansu Province in the eastern regions and the southern regions are more concentrated, while the northern and western regions are less concentrated.

\subsection{Vertical Spatial Differentiation}

The difference in altitude and topography of the traditional villages in Gansu Province directly affects the spatial differentiation and forms certain characteris- 
tics. Based on a Google Earth search of the altitude of traditional villages in Gansu Province, the altitude data span of the traditional villages in Gansu Province is large. The lowest is Zhengjiashe, Bikou Township, Wenxian County, Longnan City, with an altitude of $659 \mathrm{~m}$, and the highest is Zhagana Village, Diebu County, Gannan City, with an altitude of $2950 \mathrm{~m}$. If the villages are grouped using $500 \mathrm{~m}$ as the interval value of elevation, the traditional villages are located between $1000 \mathrm{~m}$ - $1499 \mathrm{~m}$ and $1500 \mathrm{~m}$ - $1999 \mathrm{~m}$ above the mean sea level (Figure $5)$. The traditional villages are clustered along the upper reaches of the Yellow River to the southeast, and the distribution of the prefectures and cities is related to the geomorphic types.

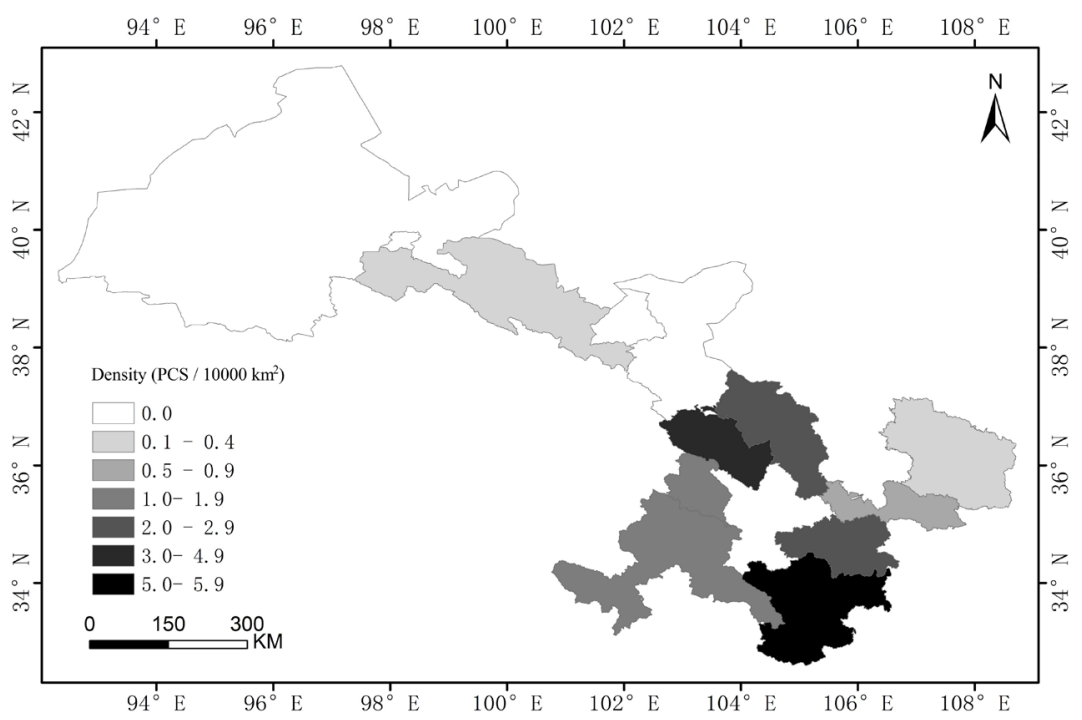

Figure 2. Density map of traditional villages in Gansu Province.

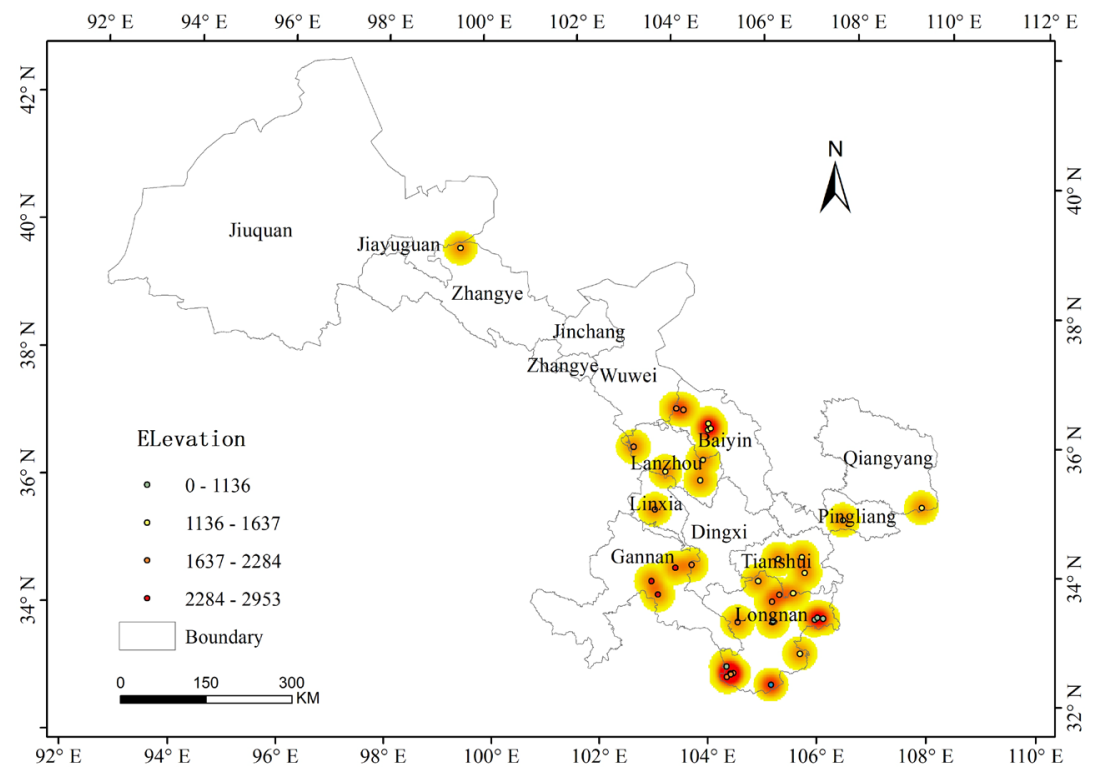

Figure 3. Kernel density and elevation distribution of the traditional villages in Gansu Province (30 km bandwidth). 


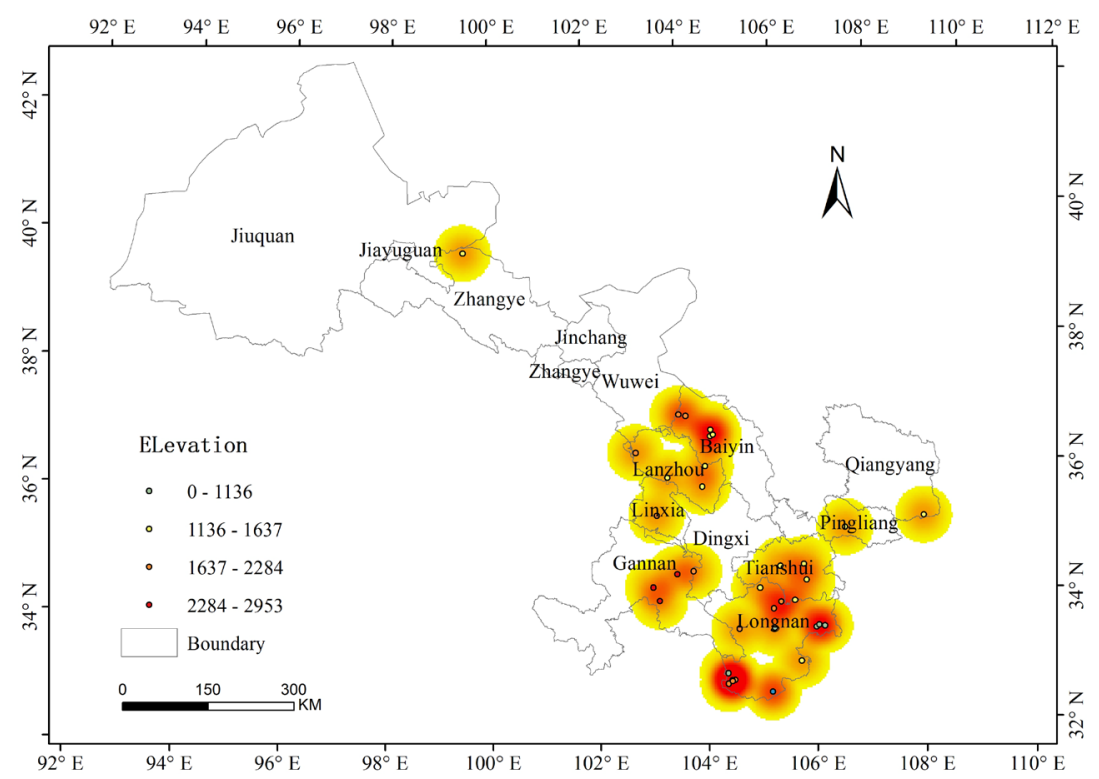

Figure 4. Kernel density and elevation distribution of traditional villages in Gansu Province (50 km bandwidth).

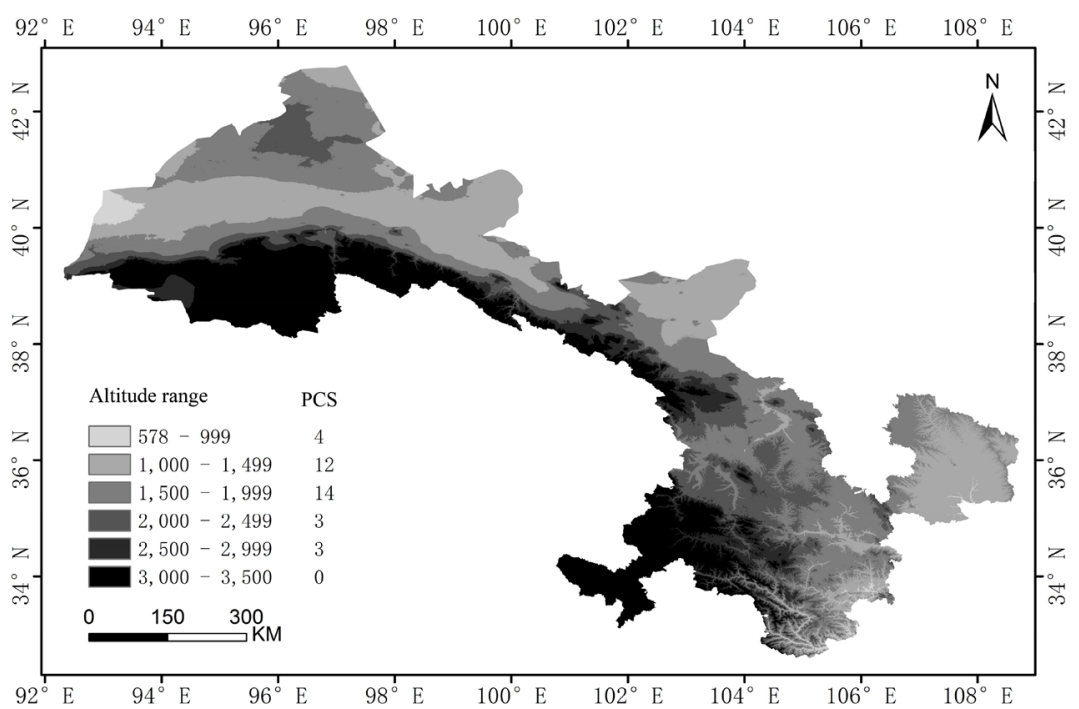

Figure 5. Spatial distribution of traditional villages in Gansu Province.

\subsection{Spatial Autocorrelation}

The analysis of the overall Moran's I of the spatial distribution of traditional villages in Gansu Province is shown in Figure 6. The calculated value of Moran's I is -0.0095 . Moran's $\mathrm{I}<0$ indicates the spatial negative correlation. The smaller the value, the greater the spatial difference. Moran's I is -0.0095 shows that the spatial differentiation of traditional villages in Gansu Province is random, showing the agglomeration of similar regions in space. According to the analysis of Moran's scatter map (Figure 6), most areas are located in the LH and HL quadrants. The spatial differentiation of traditional villages in Gansu Province shows the spatial correlation of low-value agglomeration, that is, the spatial ag- 
glomeration in the mountainous areas of South Gansu and the Loess Plateau of central Gansu. In terms of quantity, the spatial distribution of traditional villages is quite different; the scale distribution is relatively scattered, and the regional distribution is polarized.

\subsection{Analysis of the Distance between the Altitudes and the Centers}

Statistical Product and Service Solutions (SPSS) was used to analyze the altitude and center distances of traditional villages in Gansu Province. As shown in Figure 7, the traditional villages have an obviously normal distribution with altitude, and the spatial differentiation and low-value cluster, e.g. the eastern and southern regions, are relatively clustered, while the northern and western regions are less clustered. The analysis of the distances between the villages and the central cities are shown in Figure 8, which shows that the traditional villages are concentrated $10 \mathrm{~km}-20 \mathrm{~km}$ from the central city, and the number decreases with the increase in the distance.

Pearson's correlation coefficient was applied to test the correlations between the traditional village altitude and the distance from the center in Gansu Province, as shown in Table 2. The value of the Pearson coefficient is 0.087 . It is between 0.0 and 0.2 which indicates that the traditional village altitude and distance from the center in Gansu Province are weakly correlated or uncorrelated; the significance value was 0.612 which is greater than 0.05 , indicating that the correlation between the two is not strong. The distance between the traditional villages and the central city in Gansu Province is weakly related. Under the influence of different geomorphic types, the traditional villages are mainly distributed along the roads, rivers or Valley Economic Belts in the mountainous areas of South Gansu, the Loess Plateau of central Gansu, and the plateau of South Gansu.

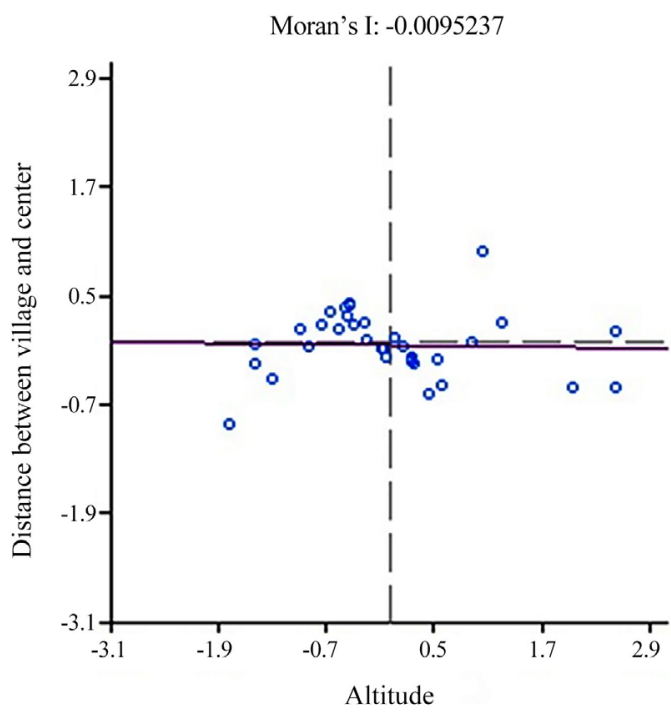

Figure 6. Moran scatter map of traditional villages in Gansu Province. 


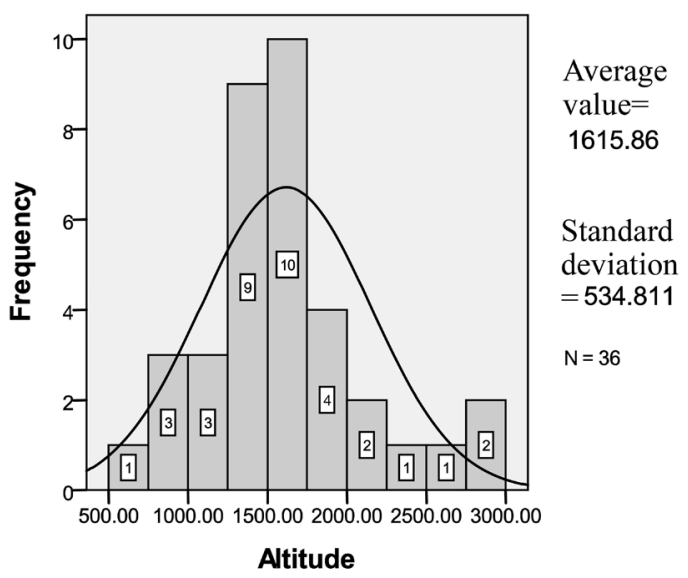

Figure 7. Normal distribution of altitude of traditional villages in Gansu Province.

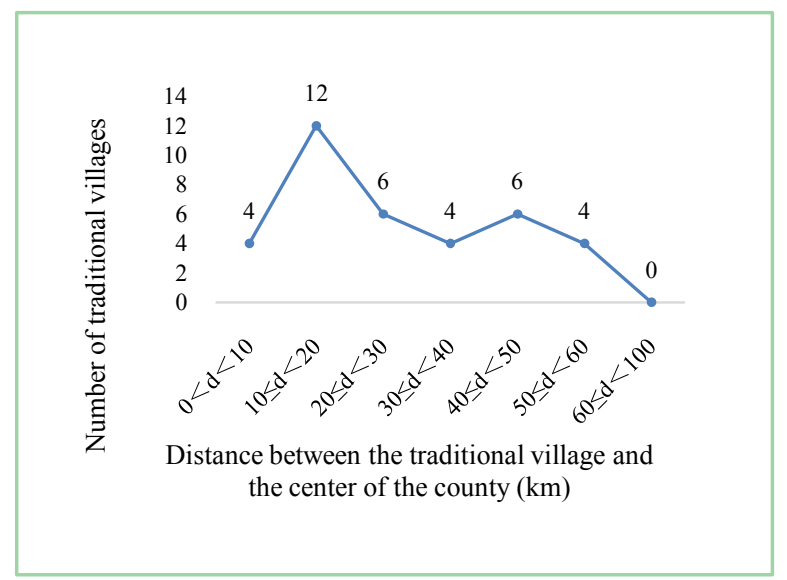

Figure 8. Distance distribution of traditional villages in Gansu Province.

Table 2. Pearson analysis of altitude and center distance of traditional villages in Gansu Province.

\begin{tabular}{cccc}
\hline Traditional villages & Correlation and significance & Altitude & Distance between centers \\
\hline \multirow{2}{*}{ Altitude } & Pearson Relevance & 1 & 0.087 \\
& Significance (bilateral) & & 0.612 \\
Distance between centers & Pearson Relevance & 0.087 & 1 \\
& Significance (bilateral) & 0.612 & \\
\hline
\end{tabular}

\section{Concluding Remarks}

The spatial autocorrelation of Moran's I in traditional villages of Gansu Province has been analyzed using the methods of spatial analysis of core density, Moran's index, correlations between elevations, and the central areas in GIS, and statistical metrology. Influenced by nature, economy, social culture and many other factors, the traditional villages in Gansu Province show significant imbalance in space. 
1) In terms of spatial differentiation, the spatial agglomeration is obvious and different, which is manifested as the agglomeration along the upper reaches of the Yellow River to the southeast, and the distribution of prefectures and cities is related to geomorphic types. The broken terrain is the main factor affecting the distribution of traditional villages.

2) In the vertical spatial distribution, the altitude data span is large. The highest is Zhagana Village in Diebu County, Gannan City, and the lowest is Zhengjiashe Village, Bikou Township, Wenxian County, and Longnan City. As the elevation increases, the number of the traditional villages in Gansu Province fluctuates, but shows an overall decrease trend. Restricted by the particularity of terrain, the influence of road, river or Valley Economic Belt on the spatial distribution of traditional villages is consistent.

3) The spatial differentiation of the traditional villages is obviously normally distributed with the altitude, and the spatial differentiation is concentrated with a low value, showing an obvious gourd-like structure, e.g. the eastern and southern areas are more concentrated, while the northern and western areas are less concentrated. Most of the traditional villages prefer to choose the river valley bottom with gentle terrain and close to the water source.

4) The spatial differentiation of traditional villages shows the characteristics of a regional difference, which is weakly related to the distance change of the central city, mainly distributed in the mountainous area of South Gansu, the loess plateau of Central Gansu, and the plateau of South Gansu. The traditional villages are concentrated in the straight-line distance of $10-20 \mathrm{~km}$ from the central town, and most of the traditional villages are within $50 \mathrm{~km}$ from the central town.

On the one hand, it has a certain economic foundation, which can develop and protect the traditional villages; on the other hand, it can avoid destroying the traditional villages because of the rapid development of economy and urbanization. This study discusses the relationship among different geomorphic types, distribution density, elevation and distance between the centers of traditional villages in Gansu Province at provincial level. The development and protection of traditional villages in the special regional environment of Gansu Province have great significance, but the study of traditional villages in Gansu Province lacks exploration of the spatial forms, locations, economic cultures, type characteristics and influence of traditional villages at the micro-level of multi-scale and multi-perspective factors. In the future, it is necessary to explore the form types and influential mechanism of spatial distribution of traditional villages in Gansu Province based on multi-scale and multi-perspective factors and the methods and approaches of the traditional villages' protection systems.

\section{Author Contributions}

Author Contributions: All the authors contributed to the algorithm and this manuscript. J L.J. and H W.Y. proposed the methodology. J L.J. performed the 
experiments and wrote the draft of the manuscript. H W.Y. visualized the diagram. J L.J. analyzed and evaluated the results. H W.Y. and J L.J. guided the research and revised the manuscript.

\section{Funding}

This research was funded by the National Key R\&D Program of China (No. 2017YFB0504203) and the National Nature Science Foundation of China (No. 41930101).

\section{Acknowledgements}

The authors are grateful to anonymous reviewers, whose comments and suggestions have helped us to improve the context and presentation of the article.

\section{Conflicts of Interest}

The authors declare no conflicts of interest regarding the publication of this paper.

\section{References}

Brunhes, J., \& Bates, E. S. (1913). The Specific Characteristics and Complex Character of the Subject-Matter of Human Geography. Scottish Geographical Magazine, 29, 304-322. https://doi.org/10.1080/14702541308554823

Bylund, E. (1960). Theoretical Considerations Regarding the Distribution of Settlement in Inner North Sweden. Geografiska Annaler, 42, 225-231.

https://doi.org/10.1080/20014422.1960.11880947

Cao, Y. C., \& Zhang, Y. K. (2013). Appraisal and Selection of "Chinese Traditional Villages" and Study on Village Distribution. Architectural Journal, 12, 44-49.

Chen, B. X., \& Nakama, Y. (2010). A Study on Village Forest Landscape in Small Island Topography in Okinawa, Japan. Urban Forestry \& Urban Greening, 9, 139-148. https://doi.org/10.1016/j.ufug.2009.12.004

Feng, Y. F., Yu, W. Y., \& Lei, R. L. (2017). Spatial Distribution Features and Controlling Factors of Traditional Villages in Guangdong Province. Scientia Geographica Sinica, 37, 236-243.

Guo, X. D., Ma, L. B., \& Zhang, Q. Y. (2013). The Spatial Distribution Characteristics and the Basic Types of Rural Settlement in Loess Hilly Area: Taking Qin'an County of Gansu Province as a Case. Scientia Geographica Sinica, 33, 45-51.

Hudson, J. C. (1969). A Location Theory for Rural Settlement. Annals of the Association of American Geographers, 59, 365-381. https://doi.org/10.1111/j.1467-8306.1969.tb00676.x

Ji, X. M., Fu, Y. Q., \& Zhu, C. L. (2015). Research on the Territorial Differentiation and Influential Factors of Chinese Traditional Villages. Journal of Shenyang Jianzhu University (Social Science), 17, 452-460.

Jiao, B. E., Shi, P. J., Liu, C. F. et al. (2013). The Distribution of Rural Settlements in Relation to Land Form Factors in Low Hilly Land on the Loess Plateau. Resources Science, 35, 1719-1727.

Jin, Q. M. (1988). The History and Current Trends of Research on Rural Settlement Geography in China. Acta Geographica Sinica, 55, 311-317. 
Kang, J. Y., Zhang, J. H., Hu, H. et al. (2016). Analysis on the Spatial Distribution Characteristics of Chinese Traditional Villages. Progress in Geography, 35, 839-850. https://doi.org/10.18306/dlkxjz.2016.07.005

Kastenholz, E., Carneiro, M. J. et al. (2012). Understanding and Managing the Rural Tourism Experience: The Case of a Historical Village in Portugal. Tourism Management Perspectives, 4, 207-214. https://doi.org/10.1016/j.tmp.2012.08.009

Lepp, A. (2007). Residents' Attitudes towards Tourism in Bigodi Village, Uganda. Tourism Management, 28, 876-885. https://doi.org/10.1016/j.tourman.2006.03.004

Lewis, C. A. (1986). Rural Settlements, Mission Settlements and Rehabilitation in Transkei. GeoJournal, 12, 375-386. https://doi.org/10.1007/BF00262360

Li, B. H., Yin, S., Liu, P. L. et al. (2015). Spatial Distribution of Traditional Villages and the Influencing Factors in Hunan Province. Economic Geography, 35, 189-194.

Liang, H. M., \& Zhao, J. (2001). Study on the Spatial Distribution Characteristics of Settlement in Loess Plateau by GIS. Human Geography, 16, 81-83.

Lipsky, Z. (1995). The Changing Face of the Czech Rural Landscape. Landscape and Urban Planning, 31, 39-45. https://doi.org/10.1016/0169-2046(94)01034-6

Liu, D. J., Hu, J., Chen, J. Z. et al. (2014). The Study of Spatial Distribution Pattern of Traditional Villages in China. China Population, Resources and Environment, 24, 157-162.

Liu, H. J., Chen, F., \& Chen, S. J. (2010). The Exterior Spatial Characteristics of the Coastal Villages of Fuzhou. Journal of Shanxi University of Science and Technology, 28, 144-148.

Lu, L., Ling, S. J., Jiao, H. F. et al. (2004). Study on Evolution Process and Mechanism of Huizhou Ancient Village. Geographical Research, 23, 686-694.

Ma, X. D., Li, Q. L., \& Shen, Y. (2012). Morphological Difference and Regional Types of Rural Settlements in Jiangsu Province. Acta Geographica Sinica, 67, 516-525.

Madu, I. A. (2010). The Structure and Pattern of Rurality in Nigeria. GeoJournal, 75, 175-184. https://doi.org/10.1007/s10708-009-9282-9

Marschalek, I. (2008). The Concept of Participatory Local Sustainability Projects in Seven Chinese Villages. Journal of Environmental Management, 87, 226-235. https://doi.org/10.1016/j.jenvman.2006.09.026

Pacione, M. (1984). Rural Geography. London: Longman Higher Education.

Packman, J., \& Pacione, M. (1986). Progress in Rural Geography. Geographical Journal, 152, 113. https://doi.org/10.2307/632978

Scott, M., \& Murray, M. (2009). Housing Rural Communities: Connecting Rural Dwellings to Rural Development in Ireland. Housing Studies, 24, 755-774. https://doi.org/10.1080/02673030903223138

Sterkenburg, J. (1990). Housing Conditions and Rural Development in Kenya. Housing Studies, 5, 130-143. https://doi.org/10.1080/02673039008720679

Sun, J. T., Niu, J. J., Zhang, K. K. et al. (2017). Spatial Distribution and Influential Factors of Traditional Villages in Shanxi. Human Geography, 32, 102-107.

Tong, Y. Q. (2014). Research on the Spatial Differentiation of Chinese Traditional Villages Based on GIS. Human Geography, 29, 44-51.

Tong, Y. Q., \& Long, H. L. (2007). The Spatial Differentiation Factors of Ethnic Traditional Villages in Guizhou. Economic Geography, 35, 133-137.

Vos, W., \& Meekes, H. (1999). Trends in European Cultural Landscape Development: Perspectives for a Sustainable Future. Landscape \& Urban Planning, 46, 3-14. 
https://doi.org/10.1016/S0169-2046(99)00043-2

Xia, K., Liu, L., \& Wang, W. (2020). Spatial Distribution of Rural Housing Abandonment and Influencing Factors at the Village Level: A Case Study of the Loess Plateau of China. GeoJournal. https://doi.org/10.1007/s10708-020-10193-5

Xiong, M. (2014). Spatial Distribution and Influence Factors of Chinese Traditional Villages. Journal of Beijing Institute of Technology (Social Sciences Edition), 16, 153-158.

Yuan, S. X., Tang, G. L., Zhang, H. O. et al. (2017). Spatial Distribution Pattern of Traditional Villages and Brief Analysis of Han Chinese Subgroup Characteristics in Guangdong. Tropical Geography, 37, 318-327. 